\title{
Cyperaceae endémicas del Perú
}

Blanca León ${ }^{1,2}$

${ }^{1}$ Museo de Historia Natural Av. Arenales 1256, Aptdo. 14-0434, Lima 14, Perú

2 Plant Resources Center, University of Texas at Austin, Austin TX 78712 EE.UU.

blanca.leon@mail.utexas.edu

\section{Resumen}

La familia Cyperaceae es reconocida en el Perú por presentar 28 géneros y 230 especies (Brako \& Zarucchi, 1993; Ulloa Ulloa et al., 2004), todas herbáceas. En este trabajo reconocemos siete endemismos en seis géneros. Se asignó las categorías de amenaza de la UICN a cinco especies. Los taxones endémicos ocupan diferentes ambientes en las regiones de la Puna Húmeda y Seca, Mesoandina y Bosque Húmedo Montano, entre los 1350 y 4200 m de altitud. Dos especies endémicas se encuentran representadas en áreas naturales protegidas.

Palabras claves: Cyperaceae, Perú, endemismo, plantas endémicas.

\section{Abstract}

The Cyperaceae are represented in Peru by 28 genera and 230 species (Brako \& Zarucchi, 1993; Ulloa Ulloa et al., 2004), all herbaceous plants. Here we recognize seven endemic taxa in six genera. We assigned IUCN threat categories to five species. The endemic taxa are found in several kinds of environments of the Dry and Humid Puna, Mesoandean, and Humid Montane Forest regions, between 1350 and 4200 m elevation. Two endemic species have been reported to occur in protected areas.

Keywords: Cyperaceae, sedges, Peru, endemism, endemic plants.

\section{Carex david-smithii Reznicek}

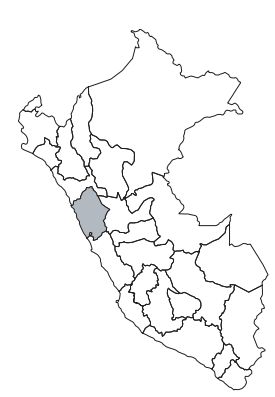

\section{EN, B1ab(iii)}

Publicación: Novon 2(4): 433, f. 1. 1992. Colección tipo: D.N. Smith et al. 12600 Herbarios: ISC, MO; CPUN!, USM!. Nombre común: Desconocido. Registro departamental: AN. Regiones Ecológicas: PSH; 4040—4200 m.

SINANPE: PNH

Herbarios peruanos: CPUN (isotipo), USM (holotipo).

Observaciones: Especie herbácea, rizomatosa, conocida sólo de tres poblaciones en el flanco oriental, de la Cordillera Blanca, donde es localmente común. Esta especie fue descubierta gracias a los estudios de David N. Smith de la flora del Parque Nacional Huascarán. Si bien habita en un área protegida, fuera de ella los ambientes propicios están afectados por los incendios intencionales y la actividad minera.

\section{Carex hebetata Boott}

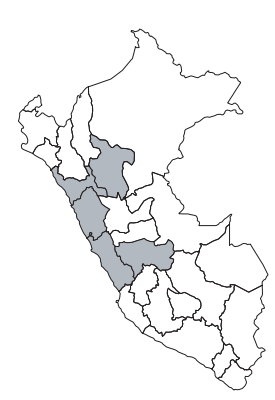

\section{VU, B1a}

Publicación: Ill. Carex 4: 172, t. 583. 1867. Colección tipo: L. Née

Herbarios: MA.

Nombre común: Desconocido.

Registro departamental: AN, JU, LL, LI, SM.

Regiones Ecológicas: PAR, AA; altitud desconocida.

SINANPE: PNH, PNRA

Herbarios peruanos: USM (2).

\section{Cyperus tacnensis Nees \& Meyen var. weberbaueri}

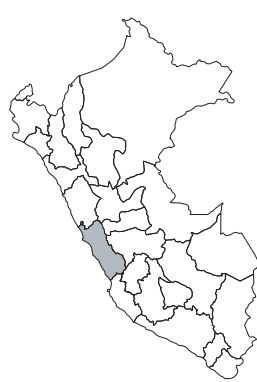
(Kük.) T.M. Pedersen

Publicación: Darwiniana 17: 543. 1972. Colección tipo: A. Weberbauer 142

Herbarios: B.

Nombre común: Desconocido.

Registro departamental: LI.

Regiones Ecológicas: DST; altitud desconocida.

SINANPE: Sin registro.

Herbarios peruanos: Ninguno.

Observaciones: Este taxón herbáceo fue considerado por Brako \& Zarucchi (1993) como un endemismo; sin embargo, no ha sido posible evaluarlo, ni asignarle una categoría.

\section{Eleocharis grossimucronata F. Mereles}

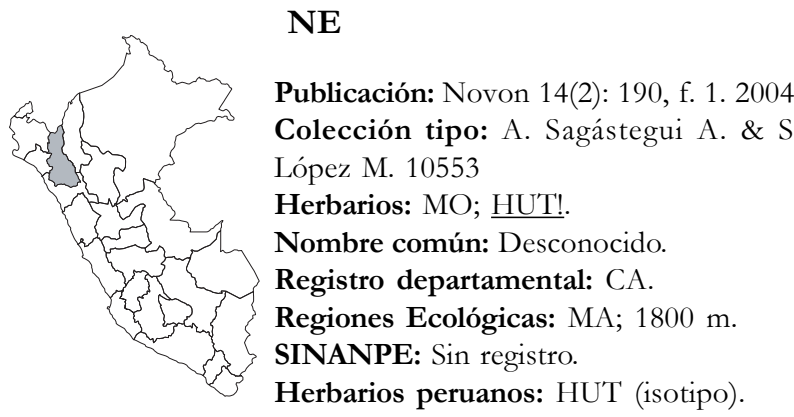

Observaciones: Esta especie se conoce solamente de una localidad, en la cuenca del Chicama, aunque su autora reconoce que podría encontrarse en Ecuador y Bolivia. Se desconoce el estado de sus poblaciones.

Observaciones: Especie herbácea conocida de varias poblaciones dispersas, en pajonales de ambas vertientes andinas, donde puede ser localmente frecuente. Amenazas a sus poblaciones podrían estar asociadas a drenaje de humedales e incendios intencionales. 


\section{Pleurostachys pearcei C.B. Clarke}

\section{DD}

Publicación: Bull. Misc. Inform., Addit. Ser. 8: 41. 1908.

Colección tipo: R.W. Pearce s.n.

Herbarios: K.

Nombre común: Desconocido. Registro departamental: Sin datos.

Regiones Ecológicas: Sin datos; $1000 \mathrm{~m}$. SINANPE: Sin registro.

Herbarios peruanos: Ninguno.

Observaciones: Esta especie fue recolectada en el siglo XIX, de una localidad desconocida que Macbride (1936) atribuyó a Tumbes.

\section{Rhynchospora killipii R. Gross}

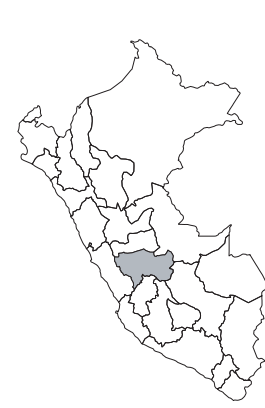

\section{DD}

Publicación: Field Mus. Nat. Hist., Bot. Ser. 11(2): 40—41. 1931.

Colección tipo: E.P. Killip \& A.C. Smith 25566

Herbarios: F, US.

Nombre común: Desconocido.

Registro departamental: JU.

Regiones Ecológicas: BMHM; 1350$1600 \mathrm{~m}$.

SINANPE: Sin registro.

Herbarios peruanos: Ninguno.

Observaciones: Hierba conocida del centro oriente del país. El ejemplar tipo fue recolectado en 1929, a lo largo de la trocha al Pichis, en la cuenca del Perené.

\section{Scirpus fragrans Ruiz \& Pav.}

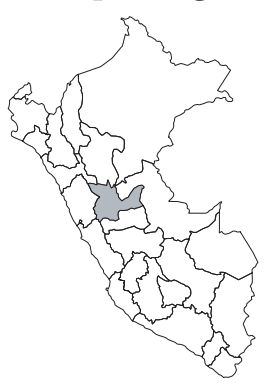

Publicación: Flora 1: 47. 1798.

Colección tipo: H. Ruiz \& J. Pavón s.n.

Herbarios: Sin datos.

Nombre común: Desconocido.

Registro departamental: HU.

Regiones Ecológicas: Sin datos; altitud desconocida.

SINANPE: Sin registro.

Herbarios peruanos: Ninguno.

Observaciones: Este taxón fue considerado por Brako \& Zarucchi (1993) como un endemismo; sin embargo, no ha sido posible evaluarlo, ni asignarle una categoría. 